\title{
HSP90alpha/beta Inhibitor TAS-116
}

National Cancer Institute

\section{Source}

National Cancer Institute. HSP90alpha/beta Inhibitor TAS-116. NCI Thesaurus. Code C134448.

A specific inhibitor of heat shock protein 90 (Hsp90) subtypes alpha and beta, with potential antineoplastic and chemo/radiosensitizing activities. Upon oral administration, Hsp90alpha/beta inhibitor TAS-116 specifically binds to and inhibits the activity of Hsp90 alpha and beta; this results in the proteasomal degradation of oncogenic client proteins, which inhibits client protein dependent-signaling, induces apoptosis, and inhibits the proliferation of cells overexpressing HSP90alpha/beta. Hsp90, a family of molecular chaperone proteins that are upregulated in a variety of tumor cells, plays a key role in the conformational maturation, stability, and function of "client" proteins within the cell,; many of which are involved in signal transduction, cell cycle regulation and apoptosis, including kinases, cell-cycle regulators, transcription factors and hormone receptors. As TAS-116 selectively inhibits cytosolic HSP90alpha and beta only and does not inhibit HSP90 paralogs, such as endoplasmic reticulum GRP94 or mitochondrial TRAP1, this agent may have less off-target toxicity as compared to non-selective HSP90 inhibitors. 